\title{
Evaluation of the Efficiency of Line-Start Permanent-Magnet Machines as a Function of the Operating Temperature
}

\author{
Colin Debruyne, Student Member, IEEE, Maria Polikarpova, Stijn Derammelaere, Member, IEEE, \\ Peter Sergeant, Member, IEEE, Juha Pyrhönen, Member, IEEE, Jan J. M. Desmet, Senior Member, IEEE, and \\ Lieven Vandevelde, Senior Member, IEEE
}

\begin{abstract}
The standard squirrel-cage induction machine has nearly reached its maximum efficiency. In order to further increase the energy efficiency of electrical machines, the use of permanent magnets in combination with the robust design and the line start capability of the induction machine is extensively investigated. Many experimental designs have been suggested in literature, but recently, these line-start permanent-magnet machines (LSPMMs) have become off-the-shelf products available in a power range up to $7.5 \mathrm{~kW}$. The permanent magnet flux density is a function of the operating temperature. Consequently, the temperature will affect almost every electrical quantity of the machine, including current, torque, and efficiency. In this paper, the efficiency of an off-the-shelf 4-kW three-phase LSPMM is evaluated as a function of the temperature by both finite-element modeling and by practical measurements. In order to obtain stator, rotor, and permanent magnet temperatures, lumped thermal modeling is used.
\end{abstract}

Index Terms-Energy efficiency, finite-element method, induction motors (IMs), magnetic losses, permanent-magnet (PM) machines, synchronous motors, temperature dependence, temperature distribution.

\section{NOMENCLATURE}

$P_{w} \quad$ Mechanical loss consisting of both friction and windage loss (in watts).

$P_{\text {iron }} \quad$ Magnetization or iron loss (in watts).

$P_{\text {joule }}$ Joule loss (in watts).

$P_{\text {SLL }} \quad$ Stray load loss (in watts).

$P_{\text {loss }} \quad$ Sum of all the losses (in watts).

$P_{\text {elk }} \quad$ Active electrical input power (in watts).

$P_{\text {mech }}$ Active mechanical output power (in watts).

$R_{T} \quad$ Resistance at temperature $T$ (in ohms).

$\alpha_{r} \quad$ Temperature dependence of $R(1 / \mathrm{K})$.

Manuscript received February 27, 2013; revised May 21, 2013 and July 31, 2013; accepted August 4, 2013. Date of publication August 22, 2013; date of current version February 7, 2014.

C. Debruyne is with the Electrical Energy Laboratory, Department of Electrical Energy, Systems and Automation, Ghent University, 9000 Gent, Belgium, and also with the Technical University Howest, 8500 Kortrijk, Belgium (e-mail: colin.debruyne@ugent.be).

M. Polikarpova and J. Pyrhönen are with the Department of Electrical Engineering, Lappeenranta University of Technology, 53850 Lappeenranta, Finland (e-mail: juha.pyrhonen@lut.fi).

S. Derammelaere, P. Sergeant, J. J. M. Desmet, and L. Vandevelde are with the Electrical Energy Laboratory, Department of Electrical Energy, Systems and Automation, Ghent University, 9000 Gent, Belgium.

Color versions of one or more of the figures in this paper are available online at http://ieeexplore.ieee.org.

Digital Object Identifier 10.1109/TIE.2013.2279127 $\alpha_{\mathrm{fe}} \quad$ Temperature dependence of steel (1/K).

$I_{\mathrm{RMS}} \quad \mathrm{RMS}$ value of the current $\left(A_{\mathrm{RMS}}\right)$.

PF Power factor $[-]$.

$\hat{B}_{p} \quad$ Peak flux density (in teslas).

$f \quad$ Supply frequency (in hertz).

$\gamma \quad$ Reversible temperature coefficient (in percentage per kelvin).

$\eta \quad$ Energy efficiency $[-]$.

$\sigma \quad$ Electrical conductivity of stator iron (in siemens per meter).

$\tau_{\text {temp }} \quad$ Thermal time constant (in seconds).

$R_{\text {cond }}$ Thermal conductance resistance (in kelvins per watt).

$R_{\text {conv }}$ Thermal convection resistance resistance (in kelvins per watt).

$S \quad$ Cross-sectional area (in square meters).

$S_{c} \quad$ Surface area (in square meters).

$l \quad$ Length of the body in the heat flow direction (in meters).

$k \quad$ Thermal conductivity (in watts per millikelvin).

$h \quad$ Convection coefficient (in watts per millikelvin).

$\mathbf{R} \quad$ Thermal resistance matrix (in kelvins per watt).

$\mathbf{P} \quad$ Segregated power loss vector (in watts).

$\Delta \mathbf{T}$ Temperature rise vector (in kelvins).

\section{INTRODUCTION}

A CORDING to [1], it seems unlikely to achieve IE4 A (Super Premium) limits [2] in the power range below $7.5 \mathrm{~kW}$ while applying the standard three-phase squirrel cage induction motor (IM) technology and still complying to the standard frame sizes, as defined in IEC60034-7 [3]. As highefficiency line-start permanent-magnet motors (LSPMMs) have evolved from fractional horsepower single-phase motors [4] into commercial three-phase machines in a power range up to $7.5 \mathrm{~kW}$ [5]-[8], LSPMMs are being suggested as one of the possibilities to achieve IE4 efficiency. A state-of-the-art review of both practical advantages and limitations of these LSPMMs has been presented in [9].

In [10], the temperature dependence of the energy efficiency of an off-the-shelf 4-kW LSPMM has been evaluated. The measurements indicated an increase in the efficiency of the LSPMM as the temperature reached nominal operating temperature. This effect is uncommon in high-power electromechanical conversion, and in order to explain this effect, the segregated losses 
TABLE I

CONSTRUCTION PARAMETERS OF THE 4-kW LSPMM

\begin{tabular}{rr}
\hline LSPMM & \\
\hline Rated speed [rpm] & 1500 \\
Rated torque [Nm] & 25 \\
Output power [kW] & 4 \\
Efficiency & $92 \%$ \\
Frame size & $112 \mathrm{M}$ \\
Insulation class & $\mathrm{F}$ \\
Stator winding connection & $\Delta$ \\
Stator windings & copper wound \\
Rotor bars & poured aluminum \\
Outer frame diameter [mm] & 193 \\
Airgap [mm] & 0.4 \\
Rotor diameter [mm] & 114.2 \\
Slots per pole and phase & 3 \\
Type of magnets & $\mathrm{NdFeB}$ \\
Remanence of PM [T] & 1.25 \\
\hline
\end{tabular}

of an LSPMM as a function of the temperature are elucidated in Section II. In Section VI, both the measurement setup and the results from [10] are addressed. However, due to practical limitations, which will be elucidated in this paper, [10] was not able to present the actual temperatures of the different motor parts; subsequently, [10] eliminated the additional stray load losses (SLLs) from the analysis.

One of the key aspects is obtaining the temperature within the different areas of the machine. In Section V, lumped thermal modeling (LTM) is applied to estimate the temperatures of the permanent magnet (PM), rotor iron, stator iron, stator windings, and motor frame. The obtained temperatures in Section VII-A validate the proposed LTM. Consequently, the thermal evaluation of [10] has been fine-tuned by adding the influence of increased temperature of the lamination steel, presenting a more accurate evaluation of the iron losses.

In this paper, finite-element modeling (FEM) is used to validate the SLL. FEM has been also implemented to evaluate the influence of the temperature rise on the iron and rotor bar loss and the resulting overall energy efficiency of the machine. The temperatures obtained by LTM are integrated in the FEM model, and the results obtained by FEM confirm an increase in efficiency with increasing operating temperature.

The machine is depicted in Fig. 9, and the internal winding distribution is presented in Fig. 4. The corresponding motor construction parameters are specified in Table I.

\section{Fundamental Loss Segregation OF AN IM AND AN LSPMM}

\section{A. Measurement of Losses According to IEC60034-2-1}

A totally enclosed fan-cooled (TEFC) LSPMM closely relates to a TEFC IM; they share identical stator winding layout, apart for the PM, a fairly similar rotor construction is noticed, and both machine frame dimensions are built according to IEC60034-7. Consequently, a segregated loss evaluation of an $\mathrm{IM}$ as a function of the operating temperature is used as a reference. The electrical losses generated in an IM are stator joule losses, rotor joule losses, and iron losses in both the stator and the rotor. In order to obtain the overall efficiency, mechanical losses caused by friction and windage should be taken into account. Contradictory, the rotor of an LSPMM rotates in synchronism with the magnetic field, and in case of an ideal field distribution, no currents are induced inside the rotor. The losses are stator joule losses, iron losses in the stator, and mechanical losses.

The Sankey diagram in Fig. 1 lists the segregated losses obtained from measurement of both a 4-kW IM and the tested LSPMM as specified in Table I. In [11], it has been addressed that the indirect measurement method is favored for small power machines. Consequently, the loss segregation for the IM IE1 in Fig. 1 has been executed according to IEC60034-2-1, i.e., the indirect measurement method. However, evaluation of the segregated losses for an LSPMM using the indirect measurement method is prohibited due to technical limitations. The reduced voltage tests are not applicable because the flux of the PM will result in excessive stator currents. A detailed analysis of the indirect measurement method according to IEC60034-2-1 with respect to the LSPMM is presented in [12]. Consequently, for the LSPMM, the stator joule and mechanical losses were determined, as elucidated in Sections III-A and C, respectively, initially assuming that the remaining loss is equivalent to the iron loss. In Fig. 1, the additional SLLs, which are caused by imperfect winding layout within the stator and the rotor, are excluded. For a standard IM, the estimation of SLL according to the indirect measurement method is still a topic of discussion [13], [14], and the indirect measurement method, which is used to determine SLL, is not straightforward applicable for an LSPMM. Consequently, the SLLs are specifically addressed in Section III-D but are initially eliminated within the fundamental loss analysis.

\section{B. Shift of Losses in an IM due to a Temperature Rise}

For an IM, friction, windage, and iron losses decrease as the temperature rises [15]. For the vast majority of IMs, the sum of stator and rotor joule losses are dominant, accounting for over $50 \%$ of the total loss in the IM [16]. The stator and rotor joule losses increase with a rising temperature; consequently, the overall efficiency changes inversely proportional to the temperature. In Fig. 2, the shift of IM losses is presented as the per unit (p.u.) shift in reference to the losses at an ambient temperature of $40{ }^{\circ} \mathrm{C}$. For an IM up to a few kilowatts, the losses increase approximately $8 \%$ between cold and hot stator windings.

\section{EVAluAtion of THE INFLUENCE OF THE TEMPERATURE ON THE LOSSES INSIDE AN LSPMM}

The goal of this paper is to obtain a similar loss evaluation for an LSPMM as presented for an IM in Fig. 2. In the following sections, the different losses of an LSPMM are evaluated as a function of the temperature. In Section III-A, the stator joule losses are elucidated. Subsequently, the iron losses are addressed in Section III-B, and the mechanical losses, i.e., $P_{w}$, are evaluated in Section III-C. SLL is described in Section III-D. As a result, an overall loss analysis as a function of the temperature is obtained in Section III-E.

\section{A. Joule Losses in an LSPMM}

If the temperature rises, the internal resistance of the stator coil will rise. This effect is formulated by

$$
R_{T}=R_{20{ }^{\circ} \mathrm{C}} \times\left(1+\alpha_{r} \Delta T\right)
$$




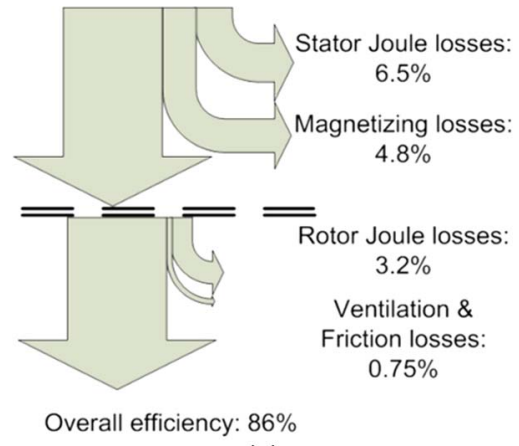

(a)

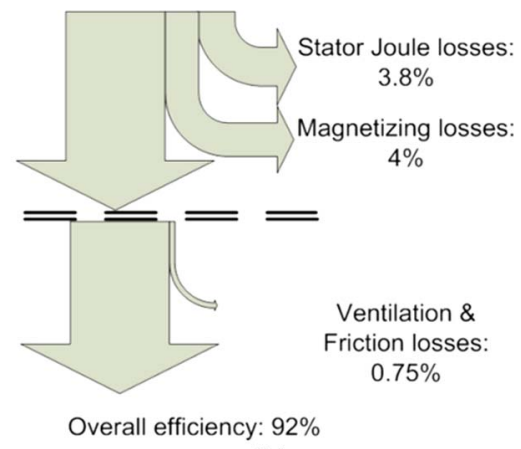

(b)

Fig. 1. Fundamental loss analysis for a 4-kW IE1 (a) IM and (B) LSPMM at nominal load condition.

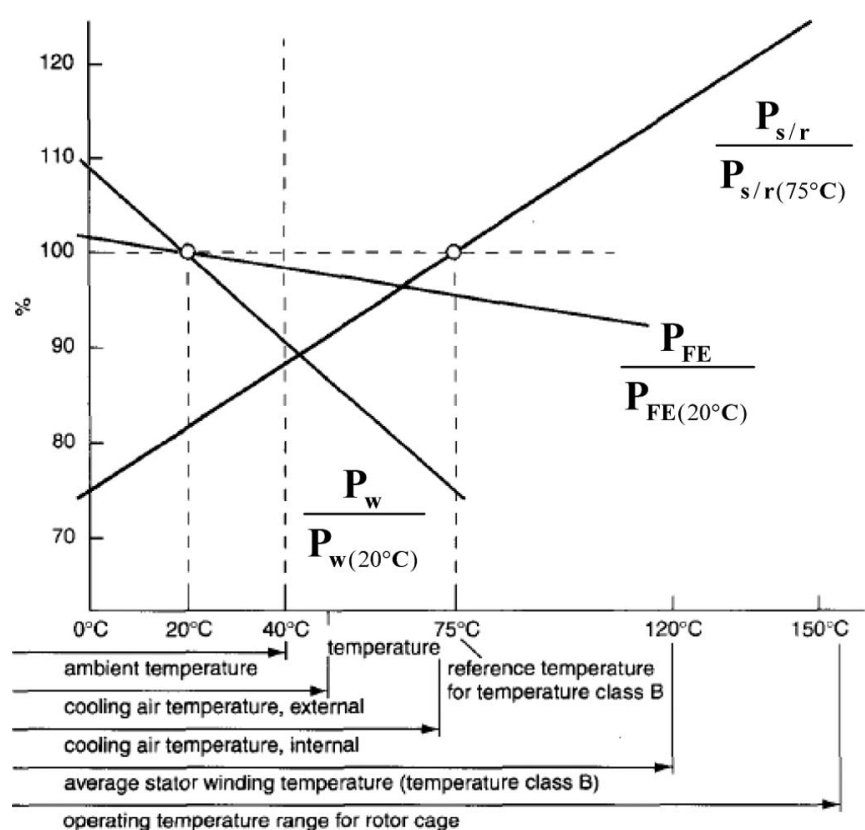

Fig. 2. p.u. shift of windage $\left(P_{w}\right)$, iron $\left(P_{\mathrm{FE}}\right)$, and stator and rotor winding losses $\left(P_{s / r}\right)$ in reference to an ambient temperature of $40{ }^{\circ} \mathrm{C}$ [15].

where $R_{T}$ is the value of the stator coil resistance at temperature $T, R_{20}{ }^{\circ} \mathrm{C}$ is the value of the resistance at a reference temperature of $20^{\circ} \mathrm{C}, \alpha_{r}$ is the temperature dependence of the resistance in $(1 / \mathrm{K})$, and $\Delta T$ is the temperature rise. Due to the small conductor sections in the coil, both skin and proximity effects are neglected [17]. If balanced conditions are assumed, the joule losses in the stator can be calculated using

$$
P_{\text {joule }}=3 \times R_{T} \times I_{\mathrm{RMS}}^{2}
$$

where $P_{\text {joule }}$ are the stator joule losses, and $I_{\mathrm{RMS}}$ is the RMS value of the phase current. Note that the reactive current demand of an LSPMM is a function of the magnet remanent flux. As this remanent flux changes with the temperature, the joule losses cannot be regarded independently from the iron losses. According to Fig. 1, the actual $P_{\text {joule }}$ of an LSPMM has been measured at $3.8 \%$ of its nominal input power.

\section{B. Iron Losses in an LSPMM}

IMs are designed to work close to the saturation level conditions. This way, the magnetic material is used at its optimum weight/energy ratio. For commonly used magnetic steel, a flux density of typically $1.5 \mathrm{~T}$ is targeted [18]. For a commercial LSPMM, the stator lamination is designed for similar flux density levels. In order to estimate the iron loss, [10] used the following Steinmetz equation:

$$
P_{\text {iron }}=C_{m} \times f^{\alpha} \times \hat{B}_{p}^{\beta}
$$

where $P_{\text {iron }}$ are the iron losses (in watts), $C_{m}$ is the first Steinmetz coefficient, $f$ is the frequency (in hertz), $\alpha$ is the second Steinmetz coefficient, $\hat{B}_{p}$ represents the peak flux density (in teslas), and $\beta$ is the third Steinmetz coefficient. However, the Steinmetz equation from (3) fails to separate the iron loss into a hysteresis, a classical, and an excess loss. For FEM, the time-domain iron loss model [19] is used as it is more accurate than the Steinmetz formula from (3), particularly in case of nonsinusoidal waveforms. A similar equation as in the cited paper computes the energy loss per cycle $W_{\mathrm{fe}}$ for a given waveform $B(t)$, i.e.,

$$
\begin{aligned}
W_{\mathrm{fe}}(B, t, T) & =a B^{\varsigma}+b(T) \int_{0}^{T_{p}} \dot{B}(t)^{2} d t \\
& +c \int_{0}^{T_{p}}|\dot{B}(t)|(\sqrt{1+e(T)|\dot{B}(t)|}-1) d t .
\end{aligned}
$$

The three terms represent the hysteresis, classical, and excess losses over one electrical period $T_{p}$. The coefficients $a, \varsigma, c$, and $e$ are to be determined by fitting based on Epstein frame measurements. The fitting procedure is explained in [20], and the coefficients are listed in Table III. The coefficient $b=\sigma d^{2} / 12$ is related to the thickness $d=0.50 \mathrm{~mm}$ of the material and the electrical conductivity $\sigma=3.24 \mathrm{MS} / \mathrm{m}$, making it dependent on the temperature $T$. As proven in [19, eq. (15)], the excess loss coefficient $e(T)$ is proportional to $\sigma$, but the coefficients $a, \alpha$, and $c$ are not. Because the conductivity depends on the temperature, the coefficients $b(T)$ and $e(T)$ are modified with the temperature by a correction factor $\left(1+\alpha_{\mathrm{fe}} \Delta T\right)$. This factor is similar to (1), but with the temperature coefficient $\alpha_{\mathrm{fe}}=$ $0.005 / \mathrm{K}$ of steel instead of the one for copper $\alpha_{r}$. The waveforms $B(t)$ are obtained by a transient 2-D FEM simulation, with rotating rotor (see Fig. 8).

The specific iron loss given by the steel manufacturer is only valid for the steel and does not represent a physical value of the actual iron loss inside a machine. First of all, when evaluating 


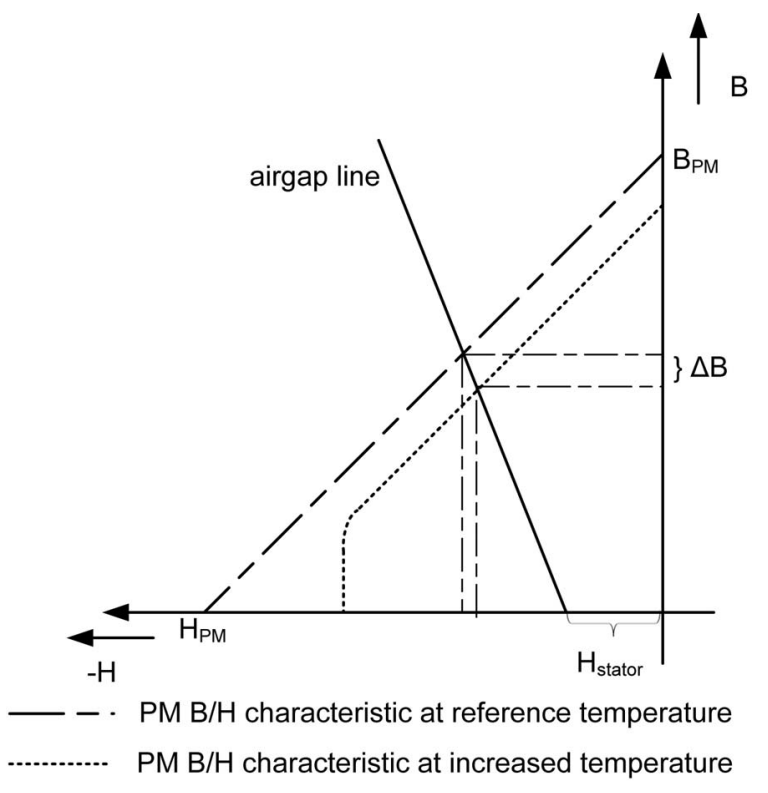

Fig. 3. Reduction of the peak induction from the PM caused by a temperature rise at identical stator current.

identical steel qualities, a spread from $14 \%$ [21] to $25 \%$ [18] of the actual losses has been reported between product batches. Second, machines are constructed by lamination resulting in practical imperfections due to mechanical operations such as cutting and stamping, insulation, and physical construction, adding more additional losses [22], [23].

The goal of this section is to evaluate the iron losses as a function of the temperature. As illustrated in Fig. 3, the peak flux density from the magnets is a function of the PM characteristics, the air gap line, and the current in the stator

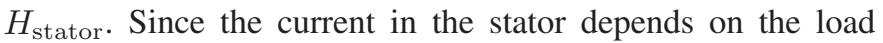
ratio of the machine, the resulting flux density is also coupled to the load ratio. It is the vector sum of the magnetomotive force both from the stator and the rotor, which determines the saturation of the machine [24]. This effect is often referred to as armature reaction. In the latter, a constant mechanical output power $P_{\text {mech }}$ is assumed, which implies that both the reduction of flux linkage of the magnets and the shift in armature reaction are solely caused by the temperature rise.

If the temperature rises, the PM remanent flux density will reduce as a function of the applied PM according to Table II [25]. These effects are well known [26], and the influence of the temperature rise is illustrated in Fig. 3.

\section{Mechanical Losses in an LSPMM}

Friction and windage losses, i.e., $P_{w}$, mainly depend on the size of the fan and the mechanical speed of the machine. For an IM, these losses can be derived by testing the machine at synchronous speed or by using IEC60034-2-1 [27]. An LSPMM rotates at synchronous speed, and because both an IM and an LSPMM share identical fan size and are constructed according to IEC 60034-7 [3], both friction and windage losses are assumed to be identical. Measurements have been executed on the described LSPMM in Table I in order to validate this assumption.
This paper evaluates the influence of temperature rise on the overall efficiency. According to [15], windage losses are inversely proportional to temperature. Reference [15] reported that pressure and ventilating power vary with air density, which, in turn, depends on air humidity, pressure, and temperature. With a relative humidity of $80 \%$ and a normal atmospheric pressure, the windage losses in the considered temperature range decrease approximately $4 \%-5 \%$ for each $10 \mathrm{~K}$ of temperature rise. As illustrated in Fig. 1, the mechanical loss for both a 4-kW $1500 \mathrm{r} / \mathrm{min}$ LSPMM and IM is $30 \mathrm{~W}$, or $0.75 \%$ of the nominal input power. Although temperature rise may have a small influence on the mechanical losses since the rotational speed is constant and the mechanical loss is marginal to other losses, the mechanical loss can initially be assumed to be constant [27]. This simplification will be justified in Section VIII.

\section{SLLs in an LSPMM}

The fundamental loss analysis of an LSPMM in Fig. 1 has indicated that, at fundamental frequency, there are no rotor losses. However, additional rotor losses do occur due to imperfect winding layout. The measurement of the SSL for an IM has proven to be quite complicated [13]; consequently, normative references such as IEC60034-2-1 give an indication of these losses, which are estimated at $0.5 \%$ of its nominal input power [14]. In Section IV, the FEM model is elucidated, and based on FEM, the SLLs are $30 \mathrm{~W}$, which is $0.6 \%$ of nominal electric power. The temperature dependence of the SLL will be addressed by FEM and will be discussed in Section VIII.

\section{E. Variation of the Efficiency as a Function of the Temperature}

The mechanical power demand $P_{\text {mech }}$ is assumed constant and at nominal load. As the temperature rises, the joule losses will increase, whereas the iron losses will decrease. The resulting influence on the losses can be expressed as

$$
\frac{d P_{\text {loss }}}{d T}=\frac{d P_{\text {joule }}}{d T}+\frac{d P_{\text {iron }}}{d T}+\frac{d P_{w}}{d T}+\frac{d P_{\text {SLL }}}{d T}
$$

where $d P_{\text {loss }}$ is the variation in losses inside the LSPMM due to the temperature shift $d T, d P_{\text {joule }}$ is the shift in joule losses in the stator, $d P_{\text {iron }}$ is the shift in iron losses in the machine, $d P_{w}$ is the shift in mechanical losses, and $d P_{\mathrm{SLL}}$ is the variation in SLL. If the temperature variation of the loss is positive, the resulting efficiency $\eta$ will decrease; if the result is negative, the efficiency will increase, i.e.,

$$
\eta=\frac{P_{\text {mech }}}{P_{\text {mech }}+P_{\text {loss }}} .
$$

\section{FEM}

\section{A. Introduction}

Because a coupled thermal/electromagnetic FEM with computational fluid dynamics (CFD) is highly time consuming [28], 
TABLE II

TEMPERATURE EFFeCTS OF COMMONLy USED PM [25]

\begin{tabular}{|c|c|c|c|c|c|c|}
\hline & Ferrite & composite Ferrite & Neoflux & composite Neoflux & SmCo & AlNiCo \\
\hline Max. Usage Temp $\left({ }^{\circ} \mathrm{C}\right)$ & 225 & $120-150$ & $80-230$ & 160 & 250 & 450 \\
\hline Reversible Temp. coefficient $\gamma(\% / \mathrm{K})$ & -0.20 & -0.2 & $-0.9 \approx 0.12$ & $-0.08 \approx 0.12$ & $-0.03 \approx 0.05$ & -0.03 \\
\hline Reversible Temp. coefficient $H_{C J}(\% / \mathrm{K})$ & $+0.2 / 0.5$ & +0.3 & $-0.45 \approx 0.85$ & -0.5 & $-0.3 \approx 0.5$ & +0.02 \\
\hline Curie Temp. $T_{C}\left({ }^{\circ} \mathrm{C}\right)$ & 460 & 450 & $310-380$ & 320 & $700-800$ & 850 \\
\hline
\end{tabular}

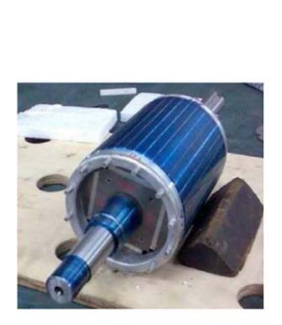

(a)

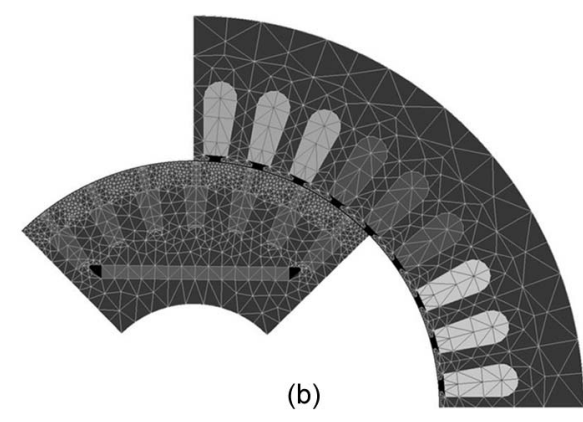

(b)
Fig. 4. (a) Rotor geometry [29]. (b) Finite-element mesh of the 4-kW LSPMM.
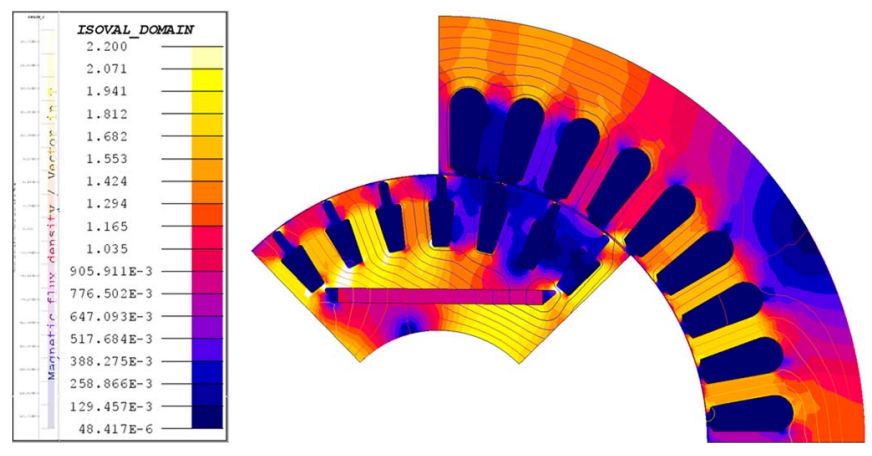

Fig. 5. Induction distribution of the 4-kW LSPMM.

this is not used for thermal modeling of the LSPMM, as will be elucidated in Section V. However, in order to correctly estimate the SLL in Section III-D and to evaluate the influence of the temperature rise on the segregated losses, including iron and rotor bar losses, FEM of the LSPMM according to the constructional parameters from Table I has been executed. The magnets are $\mathrm{NdFeB}$ magnets, with temperature-dependent remanence as listed in Table II. The mesh and the corresponding induction are plotted in Figs. 4 and 5, respectively. The FEM is a 2-D transient FEM, which is coupled to an electrical circuit. The end-winding resistance and inductance are taken into account by an impedance in series with the active part of the winding that is modeled by the 2-D FEM. In addition, for the rotor bars, the electrical circuit adds the resistance and the inductance of the rotor end ring and makes the short circuit between the 28 rotor bars.

The transient simulation starts with the rotor at synchronous speed (1500 r/min) and at nominal load torque. However, at $t=0$, the load angle is arbitrarily chosen, and the induced currents in the rotor are still zero. Therefore, transient phenomena occur (variation in speed, strong variation in currents and torque) during about $0.7 \mathrm{~s}$. The simulation is run up to $0.84 \mathrm{~s}$ with a time step of $0.1 \mathrm{~ms}$. The results presented in Figs. 6-8 are taken during the last period, where the machine is in steady state.
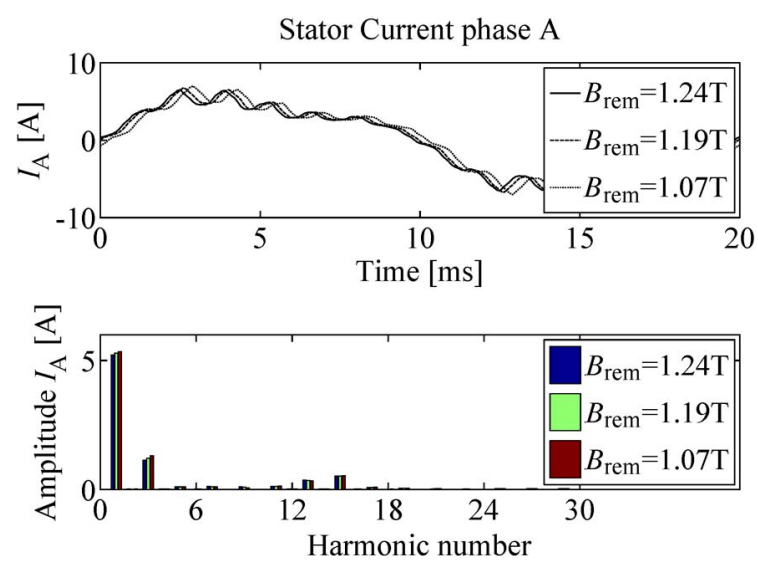

Fig. 6. Stator current for several temperatures of the machine obtained by FEM.
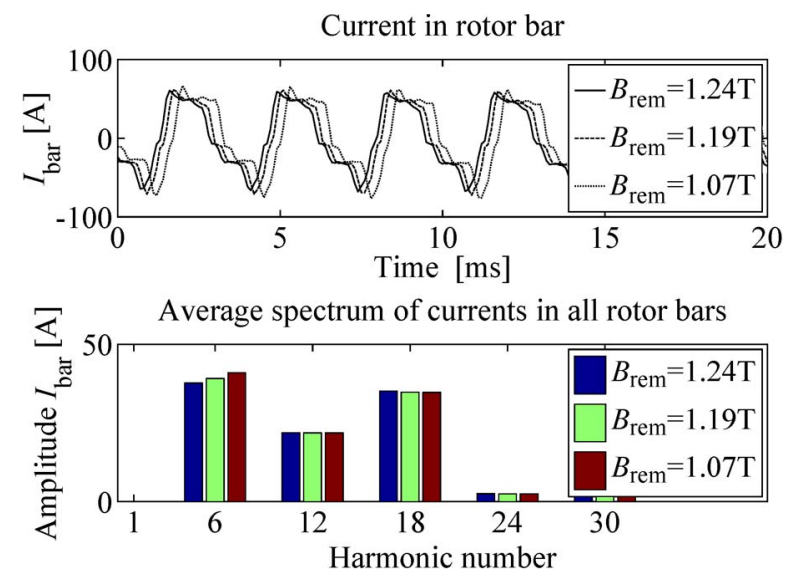

Fig. 7. Rotor current in a bar obtained by FEM and a spectrum averaged over all rotor bars for several temperatures of the machine.

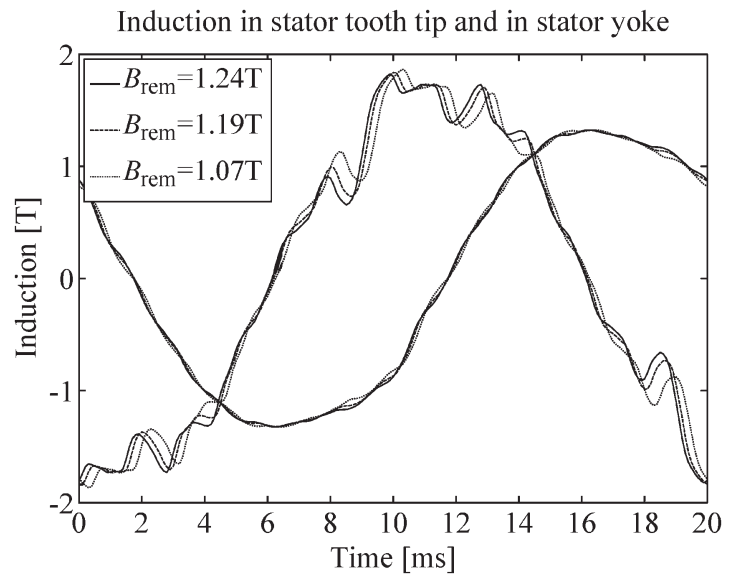

Fig. 8. Induction waveforms in the yoke (almost sinusoidal waveform) and in the tooth tip (more distorted waveform) for several temperatures of the machine obtained by FEM. 
TABLE III

Loss CoEFFICIENTS AND RESUlts OBTAINED By FEM. THE LAst Simulation Assumes DRAmatically DeCREASED Magnet REMANENCE (-14\% REMANENCE FOR 74 K TEMPERATURE RisE)

\begin{tabular}{lrrr}
\hline Magnet temperature & $20^{\circ} \mathrm{C}$ & $61^{\circ} \mathrm{C}$ & $94^{\circ} \mathrm{C}$ \\
\hline Property & $B_{\text {rem }}=1.24 \mathrm{~T}$ & $B_{\text {rem }}=1.19 \mathrm{~T}$ & $B_{\text {rem }}=1.07 \mathrm{~T}$ \\
\hline Iron loss coeff. $a[\mathrm{~J} / \mathrm{T}]$ & 0.0353 & 0.0353 & 0.0353 \\
Iron loss coeff. $\varsigma$ & 1.789 & 1.789 & 1.789 \\
Iron loss coeff. $b[\mathrm{~J} / \mathrm{T}]$ & $1.0979 \mathrm{e}-5$ & $9.265 \mathrm{e}-6$ & $7.818 \mathrm{e}-6$ \\
Iron loss coeff. $c[\mathrm{~J} / \mathrm{T}]$ & $1.876 \mathrm{e}-2$ & $1.876 \mathrm{e}-2$ & $1.876 \mathrm{e}-2$ \\
Iron loss coeff. $e[\mathrm{sec} / \mathrm{T}]$ & $2.4808 \mathrm{e}-4$ & $2.094 \mathrm{e}-4$ & $1.767 \mathrm{e}-4$ \\
\hline Stator current $\left[A_{\mathrm{RMS}}\right]$ & 3.786 & 3.852 & 3.903 \\
Power factor & 0.9488 & 0.9384 & 0.9106 \\
Stator joule loss $[\mathrm{W}]$ & 139.1 & 144.0 & 169.1 \\
Stator iron loss $[\mathrm{W}]$ & 109.3 & 102.0 & 95.3 \\
Rotor joule loss $[\mathrm{W}]$ & 34.3 & 36.5 & 38.7 \\
Ventilation loss $[\mathrm{W}]$ & 30 & 26 & 22 \\
Total loss [W] & 312.7 & 308.5 & 325.0 \\
$\eta$ & 0.9218 & 0.9229 & 0.919 \\
\hline
\end{tabular}

\section{B. Evaluation of the Temperature Dependence on the Overall} Energy Efficiency by FEM

Three FEM simulations were executed in identical conditions of supply voltage and load. The only difference was the higher temperature, resulting in reduced magnet remanence by $0.1 \%$ per kelvin, and increased rotor bar and stator winding resistances. In the postprocessing, all losses were computed in the same way. For the iron loss, the coefficients $b$ and $e$ were corrected for a temperature rise of $41 \mathrm{~K}$ (see Table III). The reason to choose a temperature rise of $41 \mathrm{~K}$ is explained further in this paper.

The results presented in Table III indicate a possible increase in efficiency as the induction increases; however, the obtained results from the FEM analysis will be discussed in detail in Section VIII.

\section{LTM}

In the thermal loss analysis, knowledge of correct temperatures of the different motor parts is of key value. As an LSPMM contains PM, this machine cannot easily be dismantled to insert temperature sensors inside. Monitoring of PM surface temperature would be challenging because the magnets are inset PMs. Although FEM and CFD should result in accurate estimations, a lot of effort and computation time is still needed to obtain temperature estimations. LTM has been suggested during the latest decade to reduce the computation time and efforts and still obtain fairly good estimations of temperatures in different parts of the machine [28], [30]-[33]. In LTM, the heat transfer is modeled analytically using calculated conduction and convection thermal resistances [34]. Because the stator is constructed from laminated steel, $\pm 70 \%$ of the generated heat is transferred in a radial direction via the stator housing. Particularly in TEFC machines, the heat transfer from the stator housing is dominating for the resulting temperatures. The convection $R_{\text {conv }}$ and conduction resistances $R_{\text {cond }}$ of the components can be obtained by

$$
\begin{aligned}
& R_{\text {conv }}=\frac{l}{S_{c} \times h} \\
& R_{\text {cond }}=\frac{l}{S \times k}
\end{aligned}
$$

TABLE IV

DOMINANT THERMAL RESISTANCES FOR A 4-kW IM AND A 4-kW LSPMM

\begin{tabular}{lcc}
\hline & IM & LSPMM \\
\hline Ambient to Frame [K/W] & 0.0322 & 0.0305 \\
Frame to Stator Yoke [K/W] & 0.0072 & 0.0072 \\
Stator Coil to Stator Yoke [K/W] & 0.0141 & 0.0141 \\
Airgap to Rotor Yoke [K/W] & 0.2933 & 0.2933 \\
\hline
\end{tabular}

TABLE V

MEASUREMENT ACCURACY

\begin{tabular}{lcc}
\hline Quantity & IEC 60034-2-1 limit & Test setup \\
\hline Electrical & $0.2 \%$ & $0.1 \%$ \\
Torque & $0.2 \%$ Full Scale & $0.1 \%$ Full Scale \\
Speed & $0.1 \%$ or $1 \mathrm{rpm}$ & $1 \mathrm{rpm}$ \\
Temperature & $1 \mathrm{~K}$ & $0.14 \mathrm{~K}$ \\
\hline
\end{tabular}

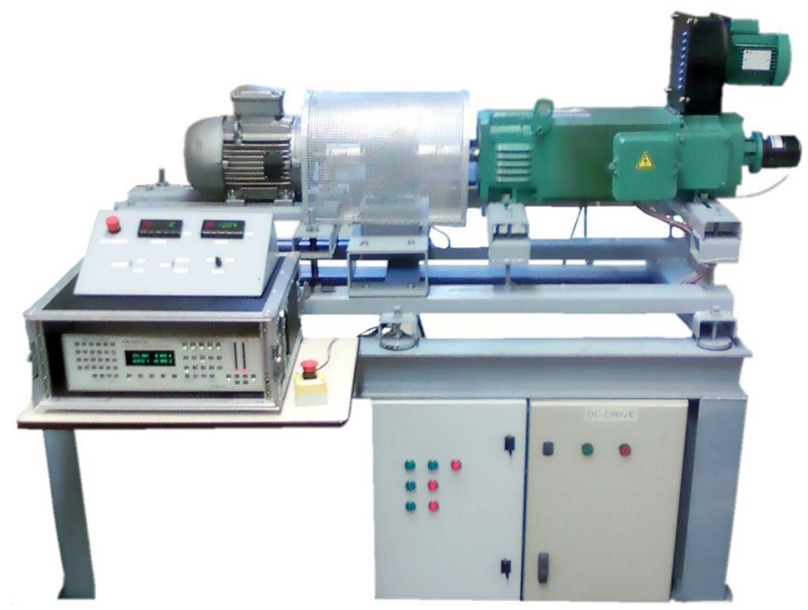

Fig. 9. General test setup.

where $l$ is the length of the body in the heat flow direction, $k$ is the thermal conductivity, $S$ is the cross-sectional area, $S_{c}$ is the surface area, and $h$ is the convection coefficient. The studied machine is divided into several components, such as frame, stator yoke, stator coils, air gap, rotor tooth, rotor winding, rotor yoke, shaft, and in the case of an LSPMM, additional rotor mounted PM. Within the resistance matrix $\mathbf{R}$, each node is coupled with its neighboring nodes. Because the physical construction of an LSPMM closely relates to an equivalent IM, an equivalent thermal resistance matrix $\mathbf{R}$ is assumed for an LSPMM. A detailed deduction of an IM LTM has been presented in [35], and this model has been tuned to a 4-kW machine. Slight modifications were needed to fine-tune the model into an LSPMM in order to include the PM, the different speed of the fan, and the adjusted rotor bars. According to Fig. 17, $83 \%$ of the heat is generated inside the stator; consequently, the most important thermal resistances are listed in Table IV.

Note that the mechanical speed of the fan increases if an IM and an LSPMM are compared. Not only does this influence the mechanical losses, according to Table IV, the absence of slip results in a $\pm 3.3 \%$ decrease in thermal frame-to-ambient resistance. Subsequently, the power losses can be segregated to the different areas in the machine and inserted into the loss matrix $\mathbf{P}$. The combination of the resistance matrix and the loss matrix results in actual temperature estimations for each node. The temperature rise $\Delta \mathbf{T}$ for each node is calculated by solving

$$
\Delta \mathbf{T}=\mathbf{R} \times \mathbf{P} .
$$




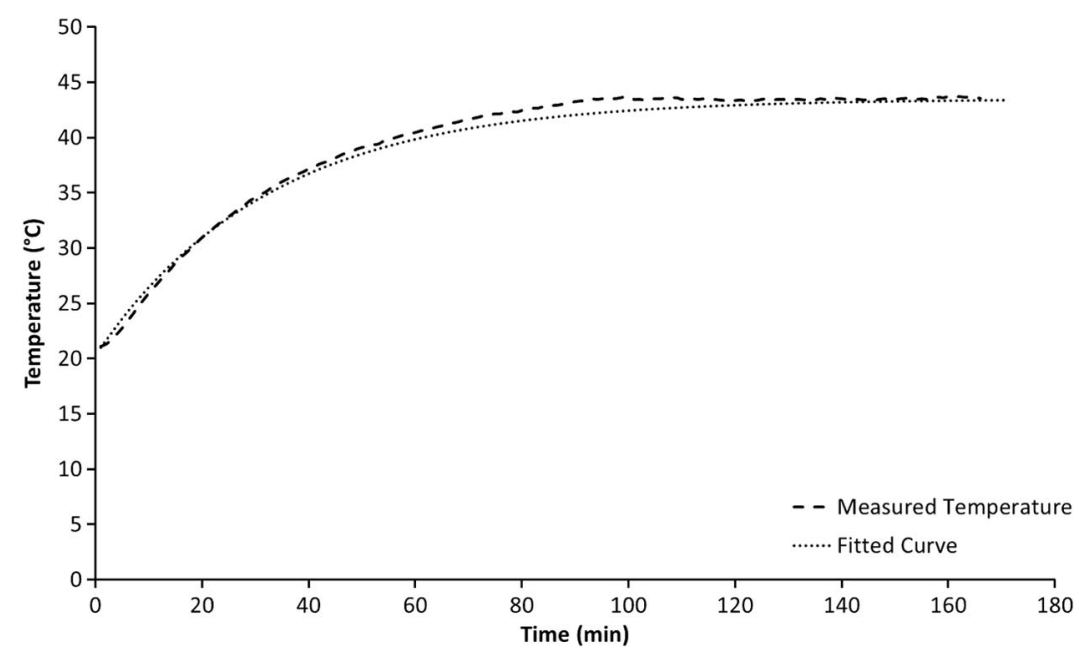

Fig. 10. Outer frame temperature as a function of the time.

Contradictory to the similar resistance matrix $\mathbf{R}$ is the segregated loss matrix $\mathbf{P}$, completely different between an IM and an LSPMM, as has been illustrated in Fig. 1 .

\section{Vi. Measurements}

\section{A. Measurement Setup}

The efficiency at nominal operating conditions is measured according to IEC 60034-2-1 using the direct method [27]. For the measurement of the electrical input power $P_{\text {elk }}$, a calibrated power analyzer is used. Currents were measured directly over the internal shunt with a current range of $30 A_{\text {peak }}$. The output torque and the speed of the machine are measured to determine the mechanical output power, and the efficiency is the ratio of the output/input active power. Both the minimal limits, as stated in [27], as the accuracy levels of the used equipment in the actual test setup are listed in Table V.

The practical test setup is depicted in Fig. 9. The LSPMM in Table I is used as a motor and is loaded at constant nominal load with a controllable de generator system in closed-loop torque control with speed limitation. The dc generator is in torque control mode, and because LSPMMs are synchronous machines, $P_{\text {mech }}$ is also constant. The motor is started up at ambient temperature and is loaded at constant nominal load until steady-state temperature is reached; no additional temperature rise is enforced. As the temperature increases, both the dc machine and the LSPMM are monitored. The mechanical output power remains constant during heating, and consequently, the temperature dependence of the speed and torque transducer are eliminated. The shift in efficiency is calculated based on a constant $P_{\text {mech }}$ and varying $P_{\text {elk }}$. Accordingly, the measurement accuracy of the $d P_{\text {loss }} / d T$ is only a function of the used power analyzer. The temperature is measured by means of thermocouples on the flanges, the ventilator, and the stator housing. The ambient temperature is measured and used as reference. The temperatures are checked with a calibrated measurement device to ensure the accuracy (see Table V).

\section{B. Measurement Results}

During the test, the temperature is monitored, and results of stator housing temperature are given in Fig. 10. As the

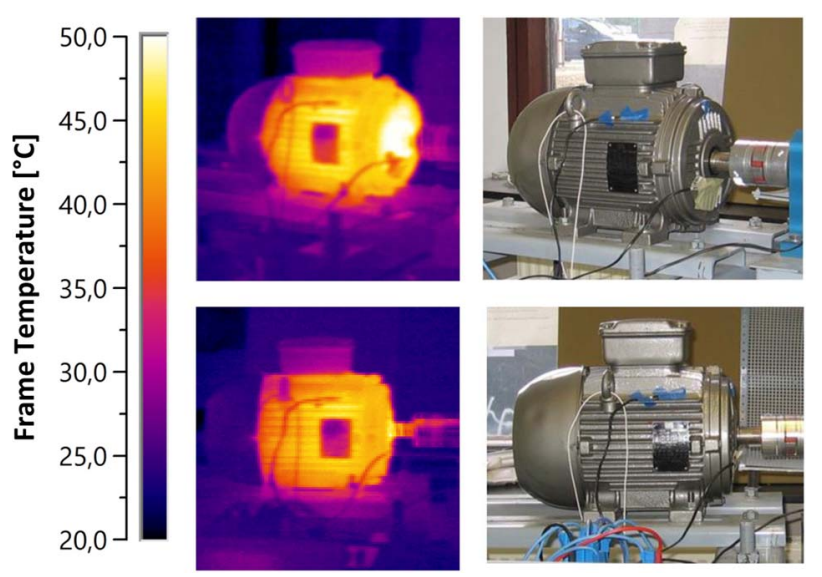

Fig. 11. Frame temperature obtained by thermal imaging of a 4-kW LSPMM at nominal load.

temperature rise can be modeled by a first-order thermal circuit consisting of thermal capacitance and a thermal resistance, the temperature rise can be formulated by (10). From the measurements, the thermal time constant $\tau_{\text {temp }}$ can be derived.

The ambient temperature $T_{0}$ is equal to $20^{\circ} \mathrm{C}$; at steady state, the outer housing temperature is $42.5^{\circ} \mathrm{C}$. At an initial time, the interval is equal to $\tau_{\text {temp }}$, and the temperature rise is equal to $63 \%$ of the steady-state temperature or, thus, $14 \mathrm{~K}$. Therefore, $\tau_{\text {temp }}$ is equal to $31 \mathrm{~min}$, i.e.,

$$
T=T_{0}+\left(1-e^{-t / \tau_{\text {temp }}}\right) \Delta T
$$

where $T_{0}$ is the reference temperature, $\tau_{\text {temp }}$ is the thermal time constant, and $\Delta T$ is the temperature increase of the frame. In order to confirm the frame's temperature rise, thermal images were taken and plotted in Fig. 11. As noticeable in Fig. 12, the efficiency increases as the LSPMM reaches the nominal operating temperature. Similar to (10), the time constant of the efficiency variation can be calculated from Fig. 12. As the same time constant $\tau_{\text {temp }}$ is obtained as in (10), this leads to the conclusion that the measured effect is solely caused by the temperature rise. 


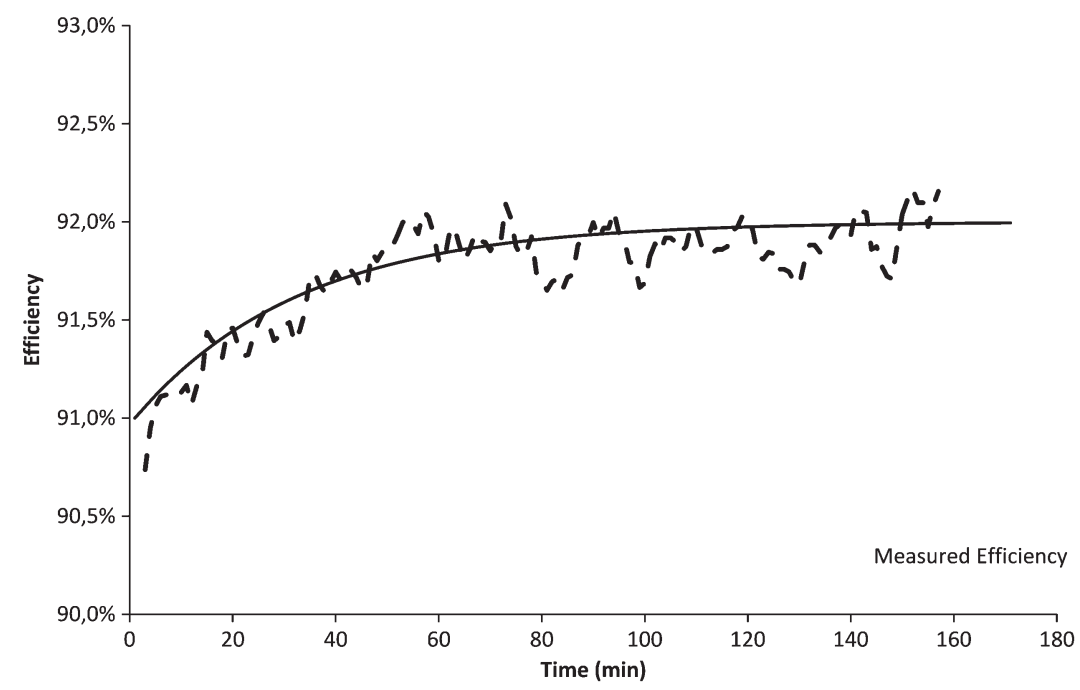

Fig. 12. Efficiency as a function of the time.

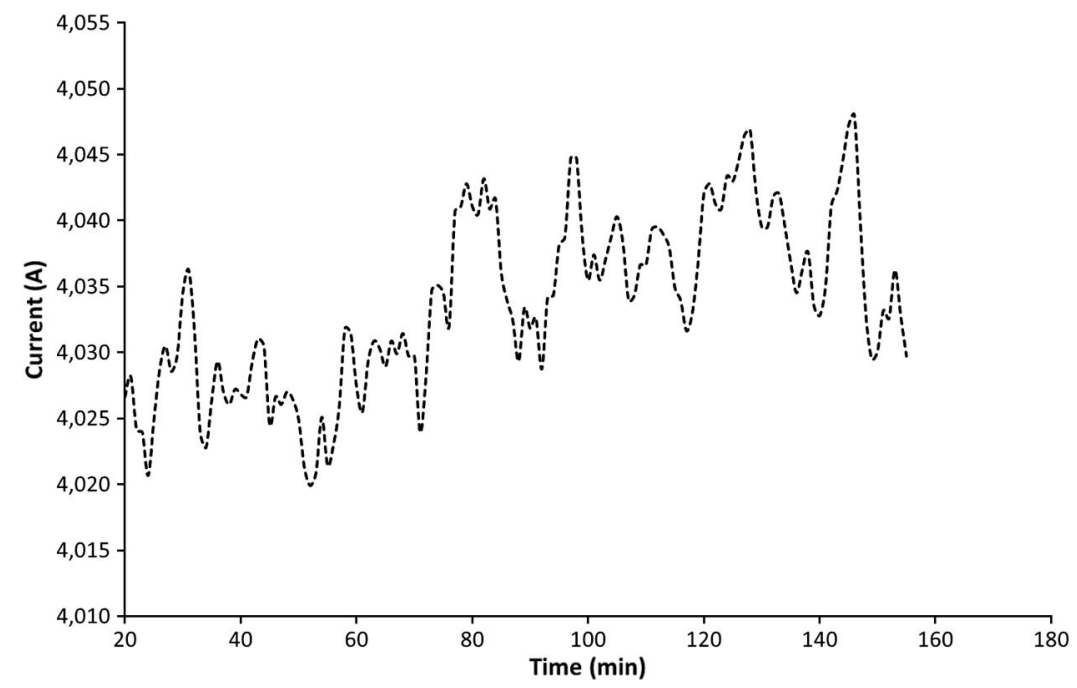

Fig. 13. $I_{\mathrm{RMS}}$ as a function of the time.

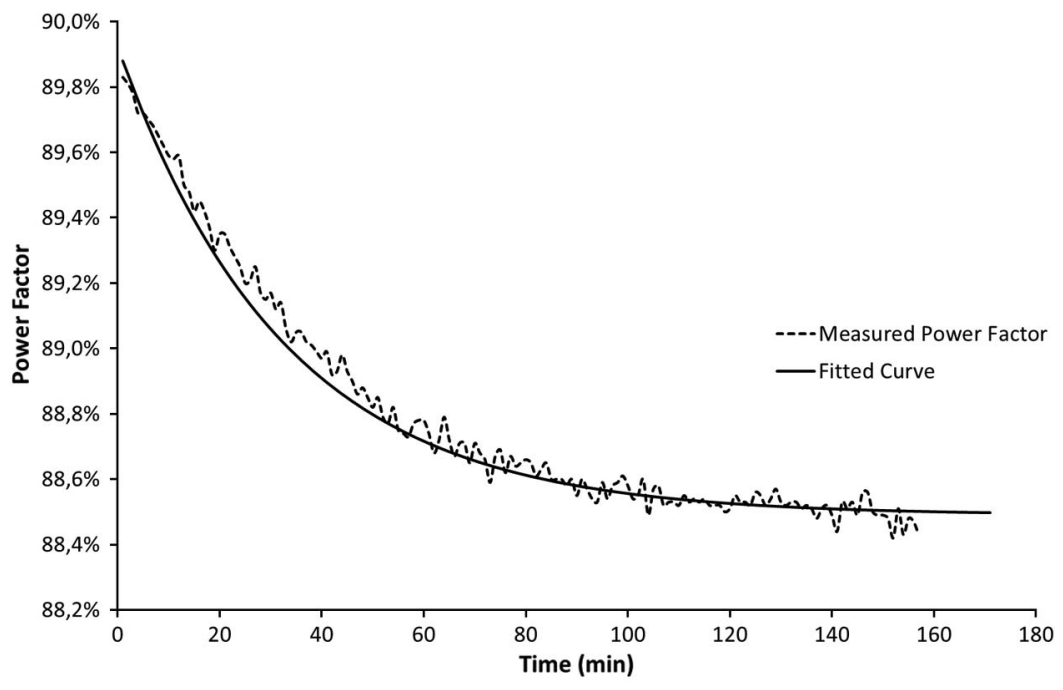

Fig. 14. PF as a function of the time.

The efficiency increases as the temperature increases, and this effect is opposite to the IM. In order to explain this effect, an in-depth loss analysis is presented, which is based on FEM (see Section IV) and on the measurement results (see Section VII-B). Additional measurements needed for Sections IV and VII-B are plotted in Figs. 13-15. 


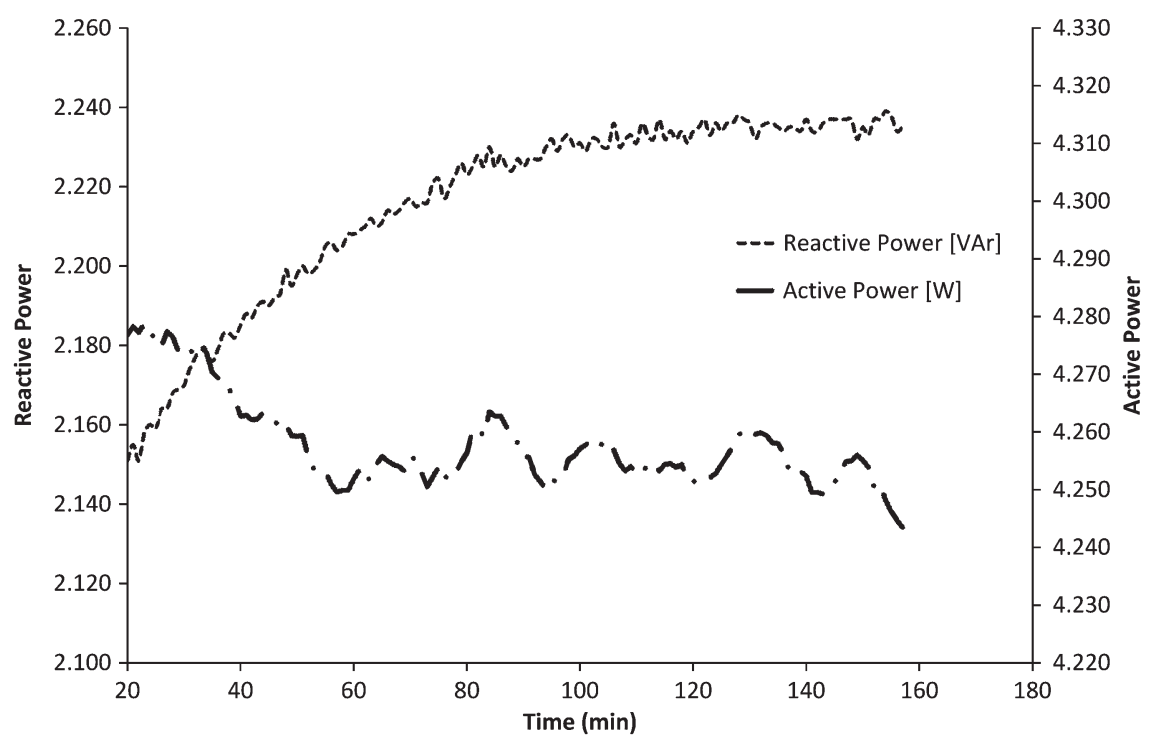

Fig. 15. Active and reactive power as a function of the time.

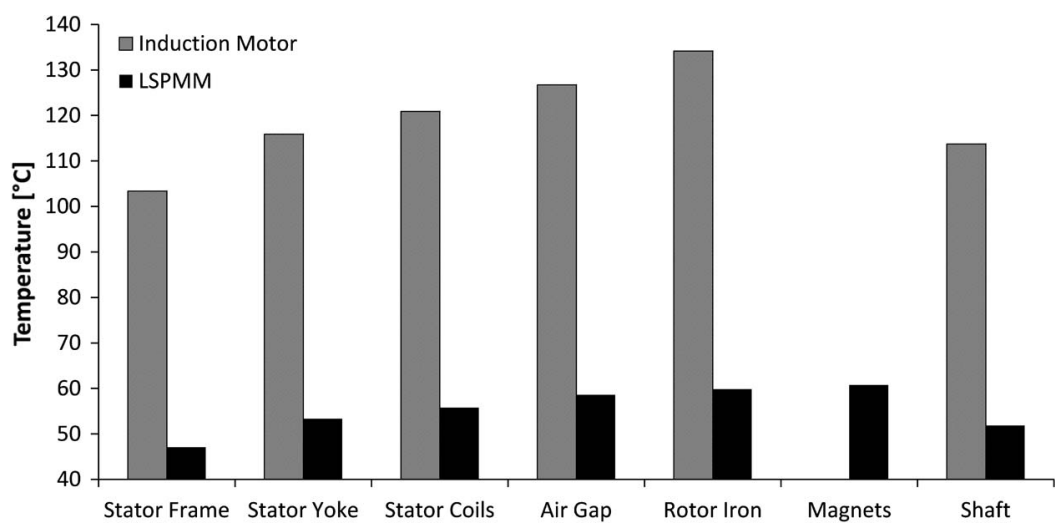

Fig. 16. Estimated temperatures of rotor iron, stator coil, and stator frame of a 4-kW IM and a 4-kW LSPMM.

TABLE VI

Temperature Motor Sections in Degrees Celsius

\begin{tabular}{rcccc}
\hline & \multicolumn{2}{c}{ IM } & \multicolumn{2}{c}{ LSPMM } \\
\hline & LTM & {$[15]$} & LTM & Measured \\
\hline Stator Yoke & 115.9 & 120 & 53.3 & - \\
Stator Coil & 120.8 & 120 & 55.8 & 57 \\
Rotor Yoke & 134.2 & 150 & 59.9 & - \\
PM & - & - & 60.8 & - \\
\hline
\end{tabular}

\section{LOSS ANALYSIS}

\section{A. Validation of the LTM}

Before discussing the influence of temperature on the overall efficiency of an LSPMM, the LTM should be validated. In Fig. 16, the comparison between a $4-\mathrm{kW}$ IM and a $4-\mathrm{kW}$ LSPMM is presented. The results were obtained using (9), and the power distribution was obtained according to Fig. 1, including SLL. The obtained temperatures of the IM correspond very well to the values listed in [15], validating the model for the IM. The correspondence between the model and the measurements is shown in Table VI.

The actual coil temperature can be recalculated from the measurement of hot and cold stator resistances using (1). At a frame temperature of $20{ }^{\circ} \mathrm{C}$, a stator resistance of $2.839 \Omega$ was measured and, subsequently, $3.264 \Omega$ at a stator housing temperature of $42^{\circ} \mathrm{C}$. The $\alpha$ of copper is equal to $3.910^{-3} \Omega / \mathrm{K}$, and consequently, a stator coil temperature of $57^{\circ} \mathrm{C}$ is obtained. The LSPMM stator coil temperature obtained by LTM differs $1.3 \mathrm{~K}$ to the calculated value, and the LSPMM outer stator frame temperature estimated by LTM differs $2.5 \mathrm{~K}$ from the values obtained by infrared measurement in Fig. 11.

In addition to a small amount of SLL, no loss is induced inside the rotor. This often results in the approximation that the temperature of the rotor and the PM could be set identical to the temperature of the stator coils [24]. The LTM indicates that there is a $5-\mathrm{K}$ difference between the stator coil and the PM. Accordingly, the obtained PM temperature of $61^{\circ} \mathrm{C}$ can be used to estimate the PM temperature. In [12], it was hinted that the LSPMM is a cool running machine in reference to a similar IM, and the obtained results confirm these conclusions.

\section{B. Loss Analysis Using the Measurement Results}

A segregated loss evaluation based on the practical measurements as a function of the frame temperature is presented in Fig. 17. 


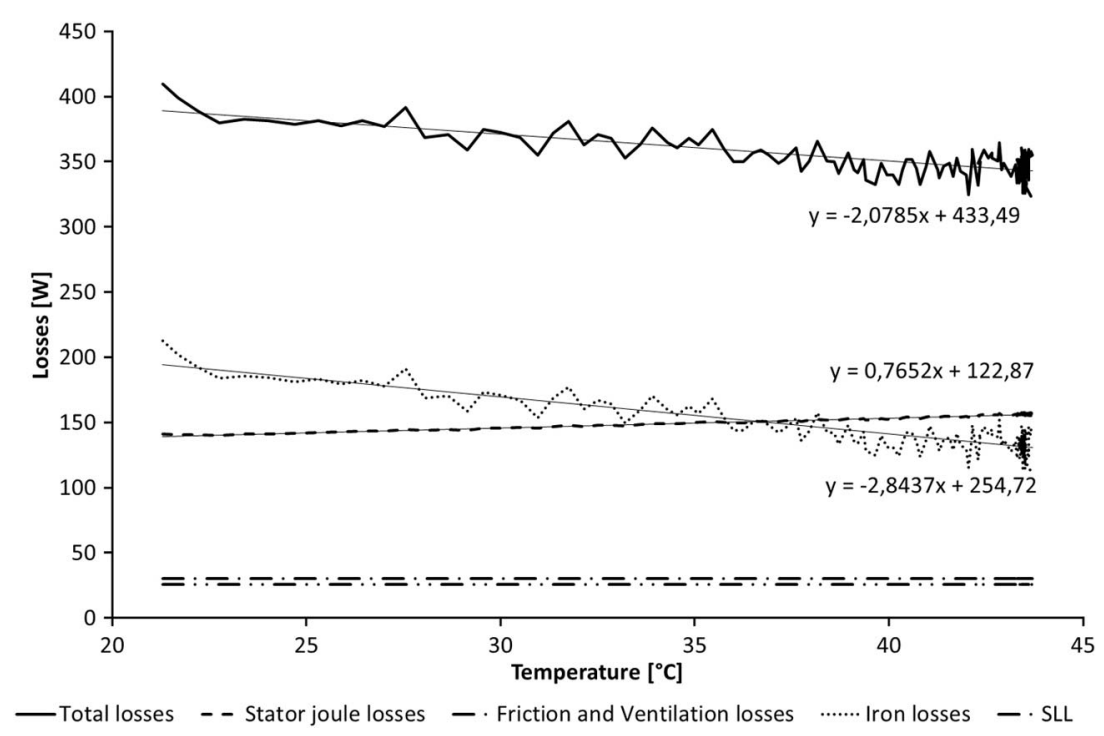

Fig. 17. Loss evaluation as a function of the frame temperature.

All calculations are done with actual measurement results. In this analysis, the mechanical loss, with an absolute value of $30 \mathrm{~W}$, and the SLL were assumed to be independent of the temperature. From the overall measured losses, the calculated joule loss, mechanical loss, and SLL obtained by FEM were subtracted, assuming that the resulting losses represent the iron losses. Note that the reference temperature is the temperature measured at the frame and not the real temperature of windings and rotor.

In Fig. 13, the current is plotted as a function of the time. The current shifts about $10 \mathrm{~mA}$ with increasing temperature, which is barely measurable and noticeable. As the joule losses are a function of $I_{\mathrm{RMS}}^{2}$, this minor shift in current does not influence the stator joule losses significantly. This is explained due to the fact that, although the reactive power increases, the active power decreases (see Fig. 15).

Within Fig. 14, it is noticed that the PF has the same $\tau_{\text {temp. }}$. This leads to the obvious conclusion that the $\mathrm{PF}$ also is a function of the temperature. As the supply voltage remains constant, the peak induction in the machine is nearly constant. With the remanence of the PM decreasing for increasing temperatures, an increased magnetizing current from the stator is needed. This explains the increase in reactive power consumption of the LSPMM. Subsequently, the efficiency of the LSPMM does slightly increase. For the same amount of active output power $P_{\text {mech }}$, this does imply a decrease in active electric power consumed by the machine.

\section{REMARKS AND DISCUSSION}

\section{A. Mechanical Loss and SLL}

In the measurement analysis, both the mechanical loss and the SLL are excluded. For mechanical losses, the increased temperature results in a reduced viscosity of both the bearing lubricant and the cooling air flow. For the IM, it is reported that there is a reduction in windage losses of $5 \%$ per $10 \mathrm{~K}$ [15]. In Fig. 2, it is observed that concerning the actual mechanical losses, this effect is not negligible. For a $4-\mathrm{kW}$
TABLE VII

COMPARISON OF FEM AND MEASUREMENTS

\begin{tabular}{lcccc}
\hline & \multicolumn{2}{c}{ FEM } & \multicolumn{2}{c}{ Measured } \\
\hline Stator coil temperature $\left[{ }^{\circ} \mathrm{C}\right]$ & 20 & 57 & 23 & 57 \\
\hline Stator current $\left[A_{\mathrm{RMS}}\right]$ & 3.786 & 3.852 & 4.021 & 4.035 \\
Power factor & 0.9488 & 0.9384 & 0.899 & 0.885 \\
Stator joule loss $[W]$ & 139.1 & 144 & 140.46 & 155.7 \\
Total loss [W] & 312.7 & 308.5 & 385 & 345.7 \\
$\eta$ & 0.9218 & 0.9229 & 0.910 & 0.917 \\
\hline
\end{tabular}

LSPMM, the mechanical losses will reduce from 30 to $26 \mathrm{~W}$ when reaching the nominal operating temperature. However, the SLLs are within the same order of magnitude of the mechanical losses. Because SLLs are mainly harmonic losses, the SLL will increase with increasing rotor bar resistance and, hence, with increasing temperature. This is observed from the FEM simulations in Table III. Because the mechanical losses decrease and the SLLs increase with increasing temperature, these effects compensate each other partially.

\section{B. FEM Evaluation of $I_{\mathrm{RMS}}, P F$, and Efficiency}

A comparison between the results obtained by FEM and the measurements is listed in Table VII.

The FEM model does result in slightly higher values of the PF in reference to the actual PF. The reason may be that the machine has a slightly lower remanent magnet flux than given by the manufacturer specifications. The measurements also indicated that the RMS current remains almost constant because the reactive power increases with temperature and the active electrical power reduces a bit. The latter is because of the decreasing losses and the constant mechanical power. FEM proves this result: The reactive power increases also in FEM, and the PF decreases. Evidently, the active power remains constant in FEM (and equal to the mechanical power) because the losses are computed a posteriori in FEM.

Nevertheless, FEM does confirm that there is a slight increase in energy efficiency as the temperature rises. FEM also illustrates that this effect is not to be extrapolated. The third 
column in Table III indicates that, at an excessive reduction in the PM remanent field, the efficiency does tend to reduce due to excessive stator loss. Consequently, there is an optimal temperature at which the LSPMM does operate at maximum efficiency.

\section{CONCLusion}

As a segregated loss evaluation of a three-phase LSPMM according to IEC60034-2-1 - the indirect method-is prohibited due to technical limitations, this paper has used FEM to address the individual loss mechanisms. All the losses are a function of the temperature, of the implemented permanent magnets, and the resulting stator current. As the operating temperature increases, the iron losses reduce, and the joule losses increase. If the decrease in the iron loss is dominant, the overall energy efficiency can increase. This effect has been validated by FEM and, consequently, confirms the measurements presented in [10].

However, before a thorough evaluation of the temperature effect can be presented, both partial loading and different power ratios of the LSPMM should be taken into account. The effect of the temperature rise on the overall efficiency is a function of the relative ratio between the segregated losses. Should the joule losses become dominant, it is possible that the overall efficiency will drop, and consequently, the conclusion of efficiency increase should not be generalized. The latter is a subject of future research.

Temperatures of the individual machine parts are essential knowledge; these are estimated using LTM. This paper suggests that slightly modified thermal models of IMs can be used to estimate temperatures inside industrial three-phase LSPMMs.

\section{REFERENCES}

[1] A. T. De Almeida, F. Ferreira, and J. A. C. Fong, "Standards for efficiency of electric motors," IEEE Ind. Appl. Mag., vol. 17, no. 1, pp. 12-19, Jan./Feb. 2011.

[2] IEC 60034-30 Ed1.0: Rotating Electrical Machines-Part 30: Efficiency Classes of Single-Speed, Three-Phase, Cage-Induction Motors (IE-Code), IEC 60034-30 Ed1.0, 2008.

[3] IEC 60034-7 Ed. 2.1 Consol With AM1: Rotating Electrical MachinesPart 7: Classification of Types of Construction, Mounting Arrangements and Terminal Box Position (IM Code). Geneva, Switzerland: International Electrotechnical Commission, 2001, p. 49.

[4] M. A. Rahman, A. M. Osheiba, K. Kurihara, M. A. Jabbar, H. W. Ping, K. Wang, and H. M. Zubayer, "Advances on single-phase line-start high efficiency interior permanent magnet motors," IEEE Trans. Ind. Electron., vol. 59, no. 3, pp. 1333-1345, Mar. 2012.

[5] W. Fei, P. Luk, J. Ma, J. Shen, and G. Yang, "A high-performance linestart permanent magnet synchronous motor amended from a small industrial three-phase induction motor," IEEE Trans. Magn., vol. 45, no. 10, pp. 4724-4727, Oct. 2009.

[6] C. A. da Silva, J. R. Cardoso, and R. Carlson, "Analysis of a threephase LSPMM by numerical method," IEEE Trans. Magn., vol. 45, no. 3, pp. 1792-1795, Mar. 2009.

[7] X. Feng, L. Liu, J. Khang, and Y. Zhang, "Super premium efficient line start-up permanent magnet synchronous motor," in Proc. 19th ICEM, 2010, pp. 1-6.

[8] F. Ferreira, G. Baoming, and A. de Almeida, "Stator winding connection mode management in line-start permanent magnet motors to improve their efficiency and power factor," in Proc. 20th ICEM, 2012, pp. 775-783.

[9] A. T. De Almeida, F. J. T. E. Ferreira, and A. Quintino, "Technical and economical considerations on super high-efficiency three-phase motors," in Proc. 48th IEEE/IAS I\&CPS, 2012, pp. 1-13.
[10] C. Debruyne, S. Derammelaere, J. Desmet, and L. Vandevelde, "Temperature dependency of the efficiency of line start permanent magnet machines," in Proc. 20th ICEM, 2012, pp. 1846-1853.

[11] E. B. Agamloh, "Induction motor efficiency," IEEE Ind. Appl. Mag., vol. 17 , no. 6 , pp. 20-28, Nov./Dec. 2011.

[12] F. Ferreira and A. T. De Almeida, "Technical and economical considerations on line-start PM motors including the applicability of the IEC60034-2-1 standard," in Proc. 7th EEMODS, Alexandria, VA, USA, 2011, pp. 1-17.

[13] K. Yamazaki and Y. Haruishi, "Stray load loss analysis of induction motor comparison of measurement due to IEEE standard 112 and direct calculation by finite-element method," IEEE Trans. Ind. Appl., vol. 40, no. 2, pp. 543-549, Mar./Apr. 2004.

[14] A. I. de Almeida, F. Ferreira, J. F. Busch, and P. Angers, "Comparative analysis of IEEE 112-B and IEC 34-2 efficiency testing standards using stray load losses in low-voltage three-phase, cage induction motors," IEEE Trans. Ind. Appl., vol. 38, no. 2, pp. 608-614, Mar./Apr. 2002.

[15] H. Auinger, "Determination and designation of the efficiency of electrical machines," Power Eng. J., vol. 13, no. 1, pp. 15-23, Feb. 1999.

[16] A. Emadi and J. Andreas, Energy-Efficient Electric Motors. New York, NY, USA: Marcel Dekker, 2005.

[17] G. K. Singh, "A research survey of induction motor operation with nonsinusoidal supply wave forms," Elect. Power Syst. Res., vol. 75, no. 2/3, pp. 200-213, Aug. 2005.

[18] F. D. D'Hulster, "Optimisation platform for torque control of 8/6 SRM," Ph.D. dissertation, Faculty of Engineering: Dept. of Electrical Engineering (ESAT), KU Leuven, Flanders, Belgium, 2005.

[19] E. Barbisio, F. Fiorillo, and C. Ragusa, "Predicting loss in magnetic steels under arbitrary induction waveform and with minor hysteresis loops," IEEE Trans. Magn., vol. 40, no. 4, pp. 1810-1819, Jul. 2004.

[20] P. Sergeant and A. den Bossche, "Reducing the permanent magnet content in fractional-slot concentrated-windings permanent magnet synchronous machines," in Proc. 20th ICEM, 2012, pp. 1405-1411.

[21] S.Sprague, "An examination of magnetic property variation of specificationacceptable electrical steel," in Proc. 20th ICEM, 2012, pp. 1170-1176.

[22] A. Schoppa, J. Schneider, and J.-O. Roth, "Influence of the cutting process on the magnetic properties of non-oriented electrical steels," J. Magn. Magn. Mater, vol. 215/216, pp. 100-102, Jun. 2000.

[23] A. Schoppa, J. Schneider, and C.-D. Wuppermann, "Influence of the manufacturing process on the magnetic properties of non-oriented electrical steels," J. Magn. Magn. Mater., vol. 215/216, pp. 74-78, Jun. 2000.

[24] T. Sebastian, "Temperature effects on torque production and efficiency of PM motors using NdFeB magnets," IEEE Trans. Ind. Appl., vol. 31, no. 2, pp. 353-357, Mar./Apr. 1995.

[25] Goudsmit Magnetics, Waalre, The Netherlands, Permanent Magnets, p. 12. [Online]. Available: www.goudsmitmagnetics.com

[26] N. Bianchi, D. Durello, and A. Fasolo, "Relationship between rotor losses and size of permanent magnet machines," in Proc. IEEE Int. SDEMPED, 2011, pp. 251-257.

[27] IEC 60034-2-1: 2007 (BS EN 60034-2-1) Rotating Electrical MachinesPart 2-1: Standard Methods for Determining Losses and Efficiency from Tests (Excluding Machines for Traction Vehicles), IEC 60034-2-1: 2007, 2007.

[28] L. Alberti and N. Bianchi, "A coupled thermal electromagnetic analysis for a rapid and accurate prediction of IM performance," IEEE Trans. Ind. Electron., vol. 55, no. 10, pp. 3575-3582, Oct. 2008.

[29] A. T. De Almeida, "Beyond induction motors: LOT-30 new EU ecodesign study," presented at the Motor Summit, Zurich, Switzerland, 2012.

[30] A. Gerlando and I. Vistoli, "Improved thermal modeling of induction motors for design purposes," in Proc. 6th Int. Conf. Elect. Mach. Drives, 1993, pp. 381-386.

[31] J. Nerg, M. Rilla, and J. Pyrhonen, "Thermal analysis of radial-flux electrical machines with a high power density," IEEE Trans. Ind. Electron., vol. 55, no. 10, pp. 3543-3554, Oct. 2008.

[32] T. A. Jankowski, F. C. Prenger, D. D. Hill, S. R. O’Bryan, K. K. Sheth, E. B. Brookbank, D. F. A. Hunt, and Y. A. Orrego, "Development and validation of a thermal model for electric induction motors," IEEE Trans. Ind. Electron., vol. 57, no. 12, pp. 4043-4054, Dec. 2010.

[33] A. Boglietti, A. Cavagnino, D. Staton, M. Shanel, M. Mueller, and C. Mejuto, "Evolution and modern approaches for thermal analysis of electrical machines," IEEE Trans. Ind. Electron., vol. 56, no. 3, pp. 871882, Mar. 2009.

[34] G. Dajaku and D. Gerling, "An improved lumped parameter thermal model for electrical machines," in Proc. 19th ICEM, 2010, pp. 1-6.

[35] L. Popova, J. Nerg, and J. Pyrhonen, "Combined electromagnetic and thermal design platform for totally enclosed induction machines," in Proc. IEEE Int. SDEMPED, 2011, pp. 153-158. 


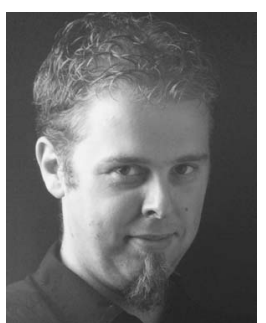

Colin Debruyne (S'11) received the Master's degree in electrotechnical engineering from the Technical University Howest, Kortrijk, Belgium, in 2004. He is currently working toward the Ph.D. degree at Ghent University, Ghent, Belgium, where he has been since 2009 and where he is researching the influence of voltage distortion on the efficiency of induction motors and line-start permanent-magnet motors.

Since 2004, he has been also a Researcher with the Technical University Howest, working in the field of power quality and general electrotechnical

engineering.

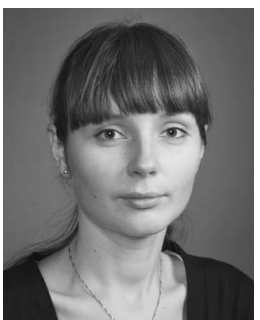

Maria Polikarpova was born in Severodvinsk, Russia, in 1985. She received the Specialist's degree in industrial heat and power from Saint Petersburg State Technological University of Plant Polymers, Saint Petersburg, Russia, in 2008, and the M.Sc. degree from Lappeenranta University of Technology (LUT), Lappeenranta, Finland, in 2009. She is currently working toward the Ph.D. degree in the Department of Electrical Engineering, LUT, where she studies heat transfer processes and cooling systems of electric motors and electric drives.

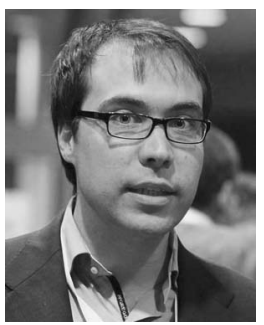

Stijn Derammelaere (M'10) was born in Kortrijk, Belgium, in 1984. He received the Master's degree in automation from the Technical University College of West Flanders, Kortrijk, Belgium, in 2006 , and the Ph.D. degree from Ghent University, Ghent, Belgium, in 2013.

$\mathrm{He}$ is currently continuing his research concerning control engineering focused on the motion control of fractional horsepower machines at Ghent University.

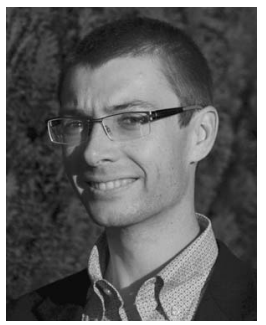

Peter Sergeant (M'12) received the M.Sc. degree in electromechanical engineering and the Ph.D. degree in engineering sciences from Ghent University, Ghent, Belgium, in 2001 and 2006, respectively.

In 2001, he was a Researcher with the Electrical Energy Laboratory, Ghent University, where he became a Postdoctoral Researcher in 2006 (Postdoctoral Fellow of the Research Foundation in Flanders). In 2008, he was a Postdoctoral Researcher with Ghent University College. Since 2012, he has been an Associate Professor with Ghent University. His current research interests include numerical methods in combination with optimization techniques to design nonlinear electromagnetic systems, in particular, electrical machines for sustainable energy applications.

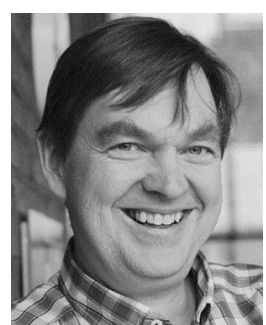

Juha Pyrhönen (M'06) born in Kuusankoski, Finland, in 1957. He received the D.Sc. degree from Lappeenranta University of Technology (LUT), Lappeenranta, Finland, in 1991.

In 1993, he was an Associate Professor of electrical engineering with LUT, where he became a Professor of electrical machines and drives in 1997. $\mathrm{He}$ is currently the Head of the Department of Electrical Engineering, Institute of LUT Energy, LUT, where he is engaged in research and development on electric motors and electric drives. His current interests include different synchronous machines and drives, induction motors and drives, and solid-rotor high-speed induction machines and drives.

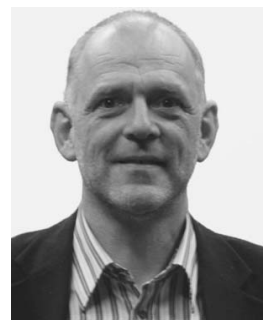

Jan J. M. Desmet (M'02-SM'11) received the B.Sc. degree in polytechnical engineering from the Polytechnic Academy, Kortrijk, Belgium, in 1983, the M.Sc. degree in electrical engineering from the Vrije Universiteit Brussel, Brussels, Belgium, in 1993, and the Ph.D. degree from the Katholieke Universiteit, Leuven, Flanders, Belgium, in 2008.

$\mathrm{He}$ is currently a Full Professor with the Technical University Howest Ghent University, Kortrijk, where he teaches power quality, renewables, grid management, and industrial electric measurement

techniques.

Prof. Desmet is a member of the International Association of Science and Technology for Development, SC77A (International Electrotechnical Commission), and TC210 (European Committee for Electrotechnical Standardization).

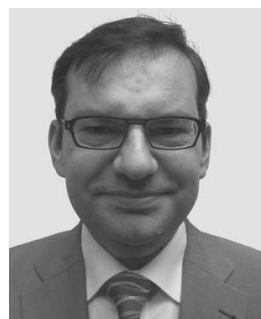

Lieven Vandevelde (M'05-SM'07) was born in Eeklo, Belgium, in 1968. He received the M.Sc. degree in electromechanical engineering and the Ph.D. degree from Ghent University, Ghent, Belgium, in 1992 and 1997, respectively.

Since 1992, he has been with the Electrical Energy Laboratory, Ghent University, where he has been also a Professor in electrical power engineering since 2004. He is currently also the Director of the knowledge platform Power-Link, which is active in the field of sustainable and renewable energy. His research and teaching activities are in the field of electrical power systems, electrical machines, and (computational) electromagnetics. 